\title{
Micro and Small Enterprises in Dire Dawa Administration: Marketing Mix Challenges and Opportunities and Their Implication on Sales Turnover
}

\author{
Yalew Mamo $^{1}$ Temesgen Yitbarek ${ }^{2}$ \\ 1.College of Business and Economics, Dire Dawa University \\ 2.College of Business and Economics, Debre Berhan University
}

\begin{abstract}
The purpose of this study is to examine the main marketing challenges and opportunities of micro and small enterprises in Dire Dawa City by considering the product, price, promotion, and place as the independent variables and sales turnover as dependent variables. Methodologically the researchers used cross-sectional descriptive study and targeted 548 enterprises grouped as manufacturing, construction, and urban agriculture. From the total target populations 226 enterprises selected based on stratifies sampling methods. Standardized questioners developed and distributed for those selected enterprises and interviews conducted for experts in Dire Dawa Urban Job Creation and Food security agency. Collected data analyzed and interpreted accordingly. The finding of regression analysis indicates that product, Price, and place have a significant effect on micro and small enterprises sales turnover while promotion has an insignificant effect. In addition to this, micro and small enterprises in Dire Dawa City have many opportunities and challenges. Government support and market demand are the major opportunities while lack of coordination among different government offices and lacking of micro and small enterprise owner's commitment mentioned as a challenge. Therefore, strong coordination among government officials and the owner's effort on product quality and branding, pricing and distribution enable micro and small enterprise owner's to increase their sales turnover.
\end{abstract}

Keywords: Marketing Mix, Micro and Small Enterprises, Sales Turnover

DOI: $10.7176 / \mathrm{EJBM} / 13-7-03$

Publication date: April $30^{\text {th }} 2021$

\section{Background of the Study}

In this period of globalization, an increasing role is being assigned to the private sector in many developing countries. In parallel to, and as part of this shift, there has been the emergence of the micro and small enterprise sector as a significant component in economic development and employment. In many countries, this sector has increasingly been seen as a means of generating meaningful and sustainable employment opportunities, particularly for those at the margins of the economy (Ajiebefun and Daramola, 2003).

The contribution of MSEs towards employment poverty reduction, entrepreneurship, and innovation is growing in importance. The sector generates about 6.2 percent of the aggregate employment in the United States, 22.3 percent in China, about 80 percent in India, 67 percent in Japan and about70 percent in EU countries" (Carter and Jones-Evans, cited in Tegegne and Meheret 2010). It has also been observed that through the past two decades the successful Asian economies have very much benefited from the growth of the MSE sector (Tegegne and Meheret 2010).

Micro and small enterprises are noted for sizeable proportions of urban employment, and also considered as the vital component of Africa's urban economies" (Tokman, cited in Hyman 1989). The same argument pertains to the situations prevailing in Ethiopian towns and cities. In Ethiopia, the private sector is substantially dominated by the MSE operators (Solomon 2004). As discovered by the CSA survey of 2003, MSEs in Ethiopia account for the bulk of non-agricultural economic activities and nearly 95.6 percent of total industrial employment. As of Dire Dawa Administration is concerned, the sector creates employment opportunities for 94,243 individuals between 2010 and 2014 (DDA Enterprise Directorate Profile, 2016).

The micro and small enterprises sector produce a wide range of products, from simple consumer goods to high precision and sophisticated products. As ancillaries, they produce a variety of parts and components required by large enterprises. Thus, marketing constitutes a key component in creating growth in micro and small businesses and is probably the most important expenditure for micro and small enterprises. Without it, the firm's target market may never know about its products or why buying from a particular producer is preferable to the competition; thus, the firm's product or service goes unnoticed and un-purchased.

\section{Statement of the Problem}

The contribution of micro and small enterprises MSEs to employment, growth and sustainable development is widely acknowledged. MSEs are long recognized as important vehicles of economic diversification, income generation, and distribution, and accelerating the economy of a country. They can also help to achieve a more 
equitable distribution of the benefits of economic growth and thereby help alleviate some of the problems associated with uneven income distribution.

No wonder that the government, particularly in developing countries has made tremendous efforts and establish policies to enhance the capacity of micro and small-scale enterprises (Cunningham and Lischeron, 2000). Perhaps, no other development strategy has enjoyed as much prominence in Ethiopia's development plans as the micro and small-scale enterprises development strategy too (Abebe E, 2000). The government has issued a national MSE development strategy in 1997 primarily because it has recognized MSEs as important vehicles to address the challenges of unemployment, economic growth, and equity in the country. The national strategy's primary objective is to create an enabling legal, institutional and another supportive environment for the growth and development of MSE. Currently, the 2010/11-2014/15 Growth and Transformation Plan (GTP) of FDRE dedicates special emphasis to the development of micro and small enterprises sector.

In Ethiopian towns and cities, MSEs and the informal sector, in general, are not only the predominant income-generating activities but also the basic means of survival. The trend, in this case, seems to extend even at a faster pace into the future. Likewise, those MSEs are believed to contribute to the economy in many different ways. Though this is normally the case, different problems are constraining their performance and ultimately have fallen short of expectations. Accordingly, many researchers have done important jobs to illustrate the challenges faced by MSEs. For instance, the study of Bereket T., (2010) in the Tigray Region, Mekelle City, has identified financial shortage, lack of entrepreneurial capability of the MSEs operators, marketing and poor technical and technology support as the major challenges of the sector. Similarly, the study of Workneh F., (2007) in Addis Ababa, Kolfe Keraneo Sub City, found a lack of capital, lack of marketing know-how, bureaucratic regulatory requirement, the problem of business development services and inappropriate locations as major challenges of the sector. But are marketing-related challenges the case in Dire Dawa Administration? To date, there has been one study commissioned by Abera (2016) to identify the major challenges and determinants of favorability of MSEs' market. Abera's study, however, has taken MSE marketing in general with no focus on the specific sectors' marketing mix elements and did not relate it to the same. Apart from this, the study didn't tell anything regarding the marketing opportunities of MSE. Therefore, this particular research attempted to feel this gap and answer the following basic research questions.

$>$ What are the main marketing challenges faced by MSEs in Dire Dawa City?

$>$ What is the relative effect of each of the marketing challenges on the sales turnover of MSEs?

$>$ To what extent are MSEs exploiting marketing opportunities?

$>$ How are MSEs applying the marketing mix elements (product, price, place, and promotion) in their businesses?

$>$ What is the government support on marketing-related challenges of MSEs if any?

\section{Objective of the Study}

The general objective of this study is to examine the main marketing challenges and opportunities for MSEs in Dire Dawa City. Specifically, this research is supposed:

$>$ To determine the relative effect of each of the marketing challenges on the sales turnover of MSE.

$>$ To identify the extent MSEs are exploiting opportunities.

$>$ To evaluate how MSEs are applying the marketing mix elements (product, price, place, and promotion) in their businesses.

$>$ To identify government marketing related support for MSE owners.

$>$ To suggest some possible ways of mitigating the marketing challenges faced by MSE.

\section{Scope of the Study}

Numerous challenges are inherent nature of MSEs. Apart from this, the MSE sector is characterized by a highly heterogeneous business entity. It is very difficult to research all sorts of challenges confronting MSEs. Partly because of this, only marketing challenges and opportunities of government prioritized sectors, i.e. Manufacturing, Construction and Urban Agriculture were considered for this study. Geographically this research focused on Dire Dawa Administration and they are nine (9) Kebeles.

\section{Literature review}

\section{Micro and Small Enterprise}

Micro, and small enterprises (MSEs) commonly known as small businesses are generally regarded as the engine of growth in many countries. This is due to their employment generation, contributions to export earnings and Gross Domestic Product (GDP). MSEs in advanced countries are major contributors to private sector employment (Olayemi and Wahid, 2014). On the other hand, the Micro and Small Enterprises (MSEs) are described as the natural home of entrepreneur-ship (Ethiopian Economic Association (EEA), 2015).

The definition of Micro and Small enterprise vary from country to country. The major variables to define 
micro and small enterprise are number of employees, Industry, and Assets/Turnover/Capital/Investment (Bloem, 2012). The council of minister clearly states the definition small business in Regulation No. 373/2016.And small manufacturing industry "means an industry having a total capital, excluding building, from Birr 100,001 to Birr 1,500,000 (One Hundred Thousand One Birr to One Million Five Hundred Thousand Birr) in the manufacturing sector and engages from 6 to 30 workers including the owner, his family members and other employees.

The amount of capital and number of employees are subjective and vary from country to country. For instance, "In Kenya, the MSME bill 2009 has used 2 criteria to define MSEs in general: Number of people/employees and the company's annual turnover. For enterprises in the manufacturing sector, the definition takes into account the investment in plant and machinery as well as the registered capital. Number of employees for micro enterprise is less than 10 people and for small enterprise more than 10 but less than 50 . On the other hand, small enterprises definitions in China industry sector hire less than 300 employees (Bloem, 2012).

\section{Micro and Small Enterprise in Ethiopia}

Most big businesses in Ethiopia have started as MSEs and have grown to their maturity over long period by cumulating capital and business management experiences. The promotion of MSEs is one of the strategic directions pursued by the government during the GTP implementation period (2010/11-2014/15), focusing on promoting the development and competitiveness of MSEs (EEA, 2015).

Micro and small enterprise development hold a strategic place within Ethiopia's Industrial Development Strategy. All the more so as MSEs are the key instruments of job creation in urban centers, whilst job creation is the centerpiece of the country's development plan. The role of MSEs as the principal job creators is not only promoted in low income countries like Ethiopia, but also high income countries including the United States of America. Accordingly, because MSEs play a pivotal role in employment creation, stimulating and strengthening MSE development should be one of Ethiopia's top development priorities. The Micro and Small Enterprise Development Policy and Strategy is evidence of the focus given to MSE development (The Micro and Small Enterprise Development Policy and Strategy prepared by Ministry of Urban Development and Housing (MoUDH), 2016).

Of MSEs, the small scale and cottage manufacturing industries has grown, on average, by 4.8 percent during the first three GTP implementation years which is lower than the average growth (6.0 percent) registered during preceding plan (PASDEP) period despite heavy promotion activities. Moreover, MSEs engaged in manufacturing activities have been growing by rate slower than the growth by large and medium scale manufacturing industries over the last decade. The share of manufacturing MSEs in GDP has declined from about 1.6 percent in 2004/05 to 1.3 percent in 2012/13. Despite the significance of their number in the economy, their share in GDP is lower than the share of large and medium scale manufacturing industries throughout the period (EEA, 2015)

\section{Marketing Mix}

Marketing, more than any other business function, deals with customers (Kotler and Armstrong, 2010). The concept of marketing defines by Pride and Ferrell (2015) marketing is the process of creating, distributing, promoting, and pricing goods, services, and ideas to facilitate satisfying exchange relationships with customers and to develop and maintain favorable relationships with stakeholders in a dynamic environment. Similarly, Perreault, Cannon and McCarthy (2012) define Marketing as the performance of activities that seek to accomplish an organization's objectives by anticipating customer or client needs and directing a flow of need satisfying goods and services from producer to customer or client. All these definitions of marketing focused on the customer's satisfaction for the profitable a company. There is no exception for Micro and Small enterprises.

The marketing program builds customer relationships by transforming the marketing strategy into action. It consists of the firm's marketing mix, the set of marketing tools the firm uses to implement its marketing strategy (Kotler and Armstrong, 2010). Marketers refer to these activities-product, pricing, distribution, and promotion - as the marketing mix because they decide what type of each element to use and in what amounts. Marketing creates value through the marketing mix. A primary goal of a marketing manager is to create and maintain the right mix of these elements to satisfy customers' needs for a general product type (Pride and Ferrell, 2015). A marketing mix - the controllable variables the company puts together to satisfy this target group (Perreault, Cannon and McCarthy, 2012).

The major marketing mix tools are classified into four broad groups, called the four Ps of marketing: product, price, place, and promotion (Kotler and Armstrong, 2010). The target market is surrounded by the controllable variables that we call the "marketing mix." A typical marketing mix includes some product, offered at a price, with some promotion to tell potential customers about the product, and a way to reach the customer's place (Perreault, Cannon and McCarthy, 2012). To deliver on its value proposition, the firm must first create a need-satisfying market offering (product) (Kotler and Armstrong, 2010). The product variable of the marketing mix deals with researching customers' needs and wants and designing a product that satisfies them (Pride and 
Ferrell, 2015).

It must decide how much it charges for the offering (price) (Kotler kand Armstrong, 2010). Price is a critical component of the marketing mix because customers are concerned about the value obtained in an exchange. Price is often used as a competitive tool, and intense price competition sometimes leads to price wars (Pride and Ferrell, 2015).

\section{Marketing Mix Challenge}

MSEs face tremendous challenges that threaten their survival and growth. The challenges include lack of or limited access to markets, financial inadequacies, limited management skills, poor work ethics and lack of competitiveness (Mutoko, 2014). Thus small scale manufacturers producing for local consumption in Nigeria face serious challenges that threaten successful marketing of their output (Olayemi and Wahid, 2014).

Prominent challenges listed in various studies in Ethiopia are access to finance, selling at less price compared with other similar enterprises, shortage of raw material, lack of experience in own business, limited access to markets, to premise, lack of training, cultural oppressions, high competition as a result of open entry to the business, development strategy and policy focuses on agriculture which in turn discourage MSEs operating in other sectors, unattractive market, lack of advertisement, training. shortage of electricity and unscheduled power cuts, bureaucratic working procedure, high tax, high collateral requirement, high interest rate, lack of technology, weak performance leading to absence of growth thinking challenges, starting business without conducting survey, inappropriate tenure, uncollectible receivables, lack of financial management skill and Youth's adverse attitude towards working under umbrella of MSEs agency (Abdulmelike, Bese, Sime, Ejigu, and Mama, 2018).

\section{Empirical Studies}

The findings of this study revealed that there is a high level of awareness of the significance roles played by marketing management strategies in the performance of MSEs; that adoption of technology in marketing management strategies can be mainstreamed into MSEs development agenda and that marketing management a strategy is a veritable tool for sustainable development of MSEs (Ardjouman, and Asma, 2015).

Findings of descriptive analyses of this study came up with a conclusion that the majority of the sampled operators of the sector face problem of lack of favorable market access; and the major reasons which are expected to be responsible for the problem were stated in rank based on their extent of seriousness across different types of selected enterprises. Besides, the types of more demandable products across different places of the city were started based on their rank of demand. A quantitative analysis of this study, involving an ordered probity-econometric regression revealed that 'types of some businesses', 'age of the enterprises' and 'variation in concentration of the same types of businesses in a given place' are the major factors which were found to be significant to influence favorability of market access of the sector. The findings of this study are limited to a sample of only four types of enterprises in the city of Dire Dawa as well as only some variables for which information can easily be accessed were considered (particularly, to analyze the first two specific objectives) (Abera, 2016).

Much an attempt was made to find out the major challenging factors for lack of market access. In the subsector of cobblestone shaping, five of the stated problems were found to be serious. These problems are ranked in terms of their extent of seriousness in descending order as the problem of the absence of advertisement, the problem of the absence of private customers, difficulty in the payment system and supplying products, nonattractiveness of selling price and problem of the lower status of recognition. (Abera, 2016)

According to Chaston (1999: 162), a common constraint facing many smaller firms is their inability to find the promotional activity of a scale sufficient to achieve parity with other, often larger, competitors. One way of overcoming this obstacle is to ally with other firms through the formation of a business network. At one end of the promotional continuum, one is increasingly encountering small firms coming together in a network to achieve greater promotional impact in a domestic market. Epstein (2006: 35) argues that word-of-mouth describes social network effects not carried by an intermediate product, but implemented directly. If businesses create a marketing program, each customer or prospect able to directly tell other potential customers about the company offers.

This objective established that respondents had an idea about marketing even though they could not give the proper definition of marketing. However, the majority of respondents indicated that they never thought about marketing and some said they did not know why they should do marketing. Therefore, this finding indicated that there is a lack of awareness and knowledge about marketing strategies and marketing activities (Mpele, 2010).

The analysis was undertaken for this research on the topic of "Marketing practices of small and mediumsized enterprises" utilized the framework of TAPE to facilitate an overview of the literature review and the research findings. Our study shows that the marketing practices of small medium-size enterprises are innovative and efficient in their operation, product development and marketing strategies. The findings illustrate that 
"transformation; assimilation and prediction (TAP) are strongly relevant to the innovative marketing activities and practices of the MSEs (Ghafoor and Hashmi, 2014).

\section{Research Methodology}

Research Design

This research is more of problem-centered and real-world practice-oriented. It is very much interested in examining the main marketing challenges and opportunities facing MSE. Therefore, in pursuance of this objective, a cross-sectional descriptive study carried out which as the same time is the most efficient and costeffective research method (Gerhardt, 2004).

\section{Sampling}

Micro and small enterprises engaged in the manufacturing, construction and urban agriculture sector serve as a target population of this study. According to Dire Dawa Administration's Micro and Small Enterprises Development Agency, there are a total of 548 registered manufacturing, construction, and urban agriculture MSEs in Dire Dawa City. Based on this total population size, the following formula suggested by Krejcie and Morgan (1970) is used to determine the sample size and the sample size turns out to be 226 with a $5 \%$ error and $95 \%$ confidence interval.

$$
\text { Sample Size }=\frac{\frac{z^{2} x p(1-p)}{e^{2}}}{1+\left(\frac{z^{2} x p(1-p)}{e^{2} N}\right.}
$$

Marginal error $(e)=5 \%$

Confidence interval $=95$ or $\mathrm{z}=1.96$

Population $(\mathrm{N})=548$

$\mathrm{P}=0.5$

$$
\text { Sample Size }=\frac{\frac{1.96^{2} \times 0.5(1-0.5)}{0.05^{2}}}{1+\left(\frac{1.96^{2} \times 0.5(1-0.5)}{0.05^{2} 548}\right.}=226
$$

The 226 sample MSEs proportionally drawn from each sector as indicated in the following table.

Table 1: Sampling Plan

\begin{tabular}{|l|l|l|l|l|}
\hline S.N. & Sector & Stage & Population Size $(\boldsymbol{N})$ & Sample Size (n) \\
\hline \multirow{4}{*}{} & \multirow{2}{*}{ Manufacturing } & Start-up & 161 & 67 \\
\cline { 3 - 5 } & & Growth & 46 & 19 \\
\cline { 3 - 5 } & Total & 207 & 86 \\
\hline \multirow{3}{*}{ Construction } & Start-up & 231 & 95 \\
\cline { 3 - 5 } & Growth & 32 & 13 \\
\cline { 3 - 5 } & Total & 263 & 108 \\
\hline \multirow{3}{*}{} & \multirow{2}{*}{ Urban Agriculture } & Start-up & 63 & 26 \\
\cline { 3 - 5 } & Growth & 15 & 6 \\
\cline { 3 - 5 } & & Total & 548 & 32 \\
\hline
\end{tabular}

Source: Micro and Small Enterprises Development Agency of Dire Dawa Administration

\section{Source of Data}

Under this study, both primary and secondary data sources were used. MSE owners/managers and Dire Dawa City's Micro and Small Enterprises Development Agency were the major sources for the collection of primary data. The secondary data were obtained from policy documents and directory profiles concerning MSEs in Ethiopia and Dire Dawa Administration, scientific research publications and books relevant to the subject under consideration. It is, however, fundamental to have a critical attitude towards this type of data and gauge its credibility. On top of this, attempts were made to use as many sources as possible that deal with similar issues.

\section{Instruments of Data Collection}

According to Creswell (2009), questionnaire surveys demands a relatively less cost and also produce a rapid return of responses. Thus, the principal data collection instrument for this study was a questionnaire. Focus Group Discussion and Interviews also carried out with purposively selected key informants (employees of MSE 
development agency) to provide insights into the problem under investigation. However, personal observations used to augment the data acquired through the questionnaires and interviews.

Reliability indicates the stability and consistencies with which the used instruments are measuring the issue studied and help assess the quality of the study. There are different ways of finding the reliability of the questionnaire. According to Nunnally (1978), the Cronbach's alpha procedure is an estimate of reliability based on the average correlation between items within each factor where 0.6 is sufficient. Thus, in this study, the result of Cronbach's alpha on the pilot and actual questionnaires used as an indicator of reliability.

According to Gay and Airasian (2003), pre-testing data collection instruments is an excellent means to ascertain validity. Accordingly, the questionnaire was put under a pilot test to learn from the process, take advantage of the strengths and correct the deficiencies. Redundant, vague, and less relevant items were reviewed, removed and missing new points were incorporated and necessary adjustments were made to come up with the final version.

\section{Method of Data Analysis and Presentation}

Data analysis was quantitative as well as qualitative. Descriptive statistics were used to ascertain the marketing challenges and opportunities facing MSE. Multiple regression analysis was used to determine the relative effect of each of the marketing challenges on the sales turnover of MSE. The resultant data were presented using tabular statistical summaries, graphs, and charts.

Data Analysis, Interpretation

Table 2: Descriptive Statistics Summary

\begin{tabular}{|l|l|l|l|}
\hline & N & Mean & Std. Deviation \\
\hline Product & 203 & 2.98 & 1.171 \\
\hline Price & 203 & 2.99 & 1.441 \\
\hline Promotion & 203 & 2.67 & 1.038 \\
\hline Place & 203 & 2.32 & .998 \\
\hline Sales Turnover & 203 & 2.69 & 1.171 \\
\hline
\end{tabular}

Table 2 indicates the summary of all marketing mixes and sales turnover. High mean scores indicate the strengths and low mean score indicates the weakness of micro and small enterprises towards sales turnover. Accordingly, the results in the table show that product (2.98) and pricing (2.99) have a relatively better mean score while place or distribution (2.32) has a relatively weaker mean score. On the other hand, promotion (2.67) and sales turnover (2.69) has a moderate mean score.

\section{Correlation Analysis}

According to Marczyk G, DeMatteo D, and Festinger D (2005), Correlation coefficients range from -1.0 to +1.0 . The sign of the coefficient represents the direction of the relationship. The coefficient (value) itself indicates the strength of the relationship. The closer it gets to 1.0 (whether it is negative or positive), the stronger the relationship. In general, correlations of .01 to .30 are considered small, correlations of .30 to .70 are considered moderate, correlations of .70 to .90 are considered large, and correlations of .90 to 1.00 are considered very large. Based on this, the following correlation is analyzed.

Table 3: Correlations between Marketing Mix and Sales turnover of Micro and Small Enterprise

\begin{tabular}{|c|c|c|c|}
\hline & & $\mathrm{N}$ & Sales \\
\hline product & $\begin{array}{l}\text { Pearson Correlation } \\
\text { Sig. (2-tailed) } \\
\text { N }\end{array}$ & 203 & $\begin{array}{l}.701^{* *} \\
.000 \\
203\end{array}$ \\
\hline Price & $\begin{array}{l}\text { Pearson Correlation } \\
\text { Sig. (2-tailed) } \\
\mathrm{N}\end{array}$ & 203 & $\begin{array}{l}.897^{* *} \\
.000 \\
203\end{array}$ \\
\hline Promotion & $\begin{array}{l}\text { Pearson Correlation } \\
\text { Sig. (2-tailed) } \\
\mathrm{N}\end{array}$ & 203 & $\begin{array}{l}.815^{* *} \\
.000 \\
203\end{array}$ \\
\hline Place & $\begin{array}{l}\text { Pearson Correlation } \\
\text { Sig. (2-tailed) } \\
\mathrm{N}\end{array}$ & 203 & $\begin{array}{l}.784^{* *} \\
.000 \\
203\end{array}$ \\
\hline
\end{tabular}

**. Correlation is significant at the 0.01 level (2-tailed). 
Table 3 item 1 represents the table of correlations. Where two variables - Product and Sales turnover- are positively correlated $(\mathrm{r}=.701, \mathrm{p}=.000)$. There is a strong relationship between these two variables which is significant. So we can say that the well-managed product of Micro and Small enterprises can generate good sales turn over for the enterprise. Micro and small enterprise work on their product differentiation, quality, and other product dimensions can maximize their sales turnover.

Table 3 item 2 represents the table of correlations. Where two variables - Price and Sales turnover- are positively correlated $(\mathrm{r}=.897, \mathrm{p}=.000)$. There is a strong relationship between these two variables which is significant. So we can say that less price and good price strategy of Micro and Small enterprises can maximize their sales turnover. Micro and small enterprise pricing strategies of their product can maximize their sales turnover.

Table 3 item 3 represents the table of correlations. Where two variables - Promotion and Sales turnoverare positively correlated $(\mathrm{r}=.815, \mathrm{p}=.000)$. There is a strong relationship between these two variables which is significant. So we can say that organized and integrated marketing promotion of Micro and Small enterprises can maximize the sale turnover of the enterprise. Micro and small enterprise work on the promotion of their product can maximize their sales turnover.

Table 3 item 4 represents the table of correlations. Where two variables - Place and Sales turnover- are positively correlated $(\mathrm{r}=.784, \mathrm{p}=.000)$. There is a strong relationship between these two variables which is significant. So we can say that the accessibility of Micro and Small enterprise products can maximize the sale turnover of the enterprise. Micro and small enterprise product accessibility can maximize their sales turnover.

\section{Regression Analysis}

According to Marczyk (2005), linear regression is a method of estimating or predicting a value on some dependent variable given the values of one or more independent variables. Like correlations, statistical regression examines the association or relationship between variables. Unlike with correlations, however, the primary purpose of regression is a prediction. There are two basic types of regression analysis: simple regression and multiple regressions. In simple regression, we attempt to predict the dependent variable with a single independent variable. In multiple regressions, we may use any number of independent variables to predict the dependent variable.

Multiple Regressions is a correlation between the observed values of $\boldsymbol{y}$, the values of $\boldsymbol{y}$ predicted by multiple regression models. Therefore, large values of the multiple Regressions represent a large correlation between the predicted and observed values of the outcome. The model summary table reports the strength of the relationship between the independent and the dependent variable; customers purchase decisions of bottled drink water.

\section{Table 4: Model Summary}

\begin{tabular}{|l|l|l|l|l|}
\hline Model & $\mathrm{R}$ & R Square & Adjusted R Square & Std. Error of the Estimate \\
\hline 1 & $.920^{\mathrm{a}}$ & .847 & .843 & .463 \\
\hline
\end{tabular}

a. Predictors: (Constant), place, product, promotion, price

In the above table, the $\mathrm{R}$ is multiple correlation coefficients between predictor and outcome, its value is 0.920. While Adjusted R Square shows the ratio of interdependence. The value of adjusted R square is which is multiplied by 100 . It that means $84.7 \%$ of the variance in the dependent variable (customers purchase decision) can be predicted from the independent variable. In this model the difference between R and R2 is not small (in fact the difference between the values is $0.847-0.843=0.004$ about $0.4 \%$ ). This shrinking means that if the model were derived from the population rather than a sample it would account for approximately $0.4 \%$ less variance in the outcome

Table 5: ANOVA ${ }^{\mathrm{a}}$

\begin{tabular}{|ll|l|l|l|l|l|}
\hline Model & & Sum of Squares & df & Mean Square & F & Sig. \\
\hline \multirow{2}{*}{1} & Regression & 234.468 & 4 & 58.617 & 272.998 & $.000^{\mathrm{b}}$ \\
& Residual & 42.514 & 198 & .215 & & \\
& Total & 276.982 & 202 & & & \\
\hline
\end{tabular}

a. Dependent Variable: Sales

b. Predictors: (Constant), place, product, promotion, price

The significant level in the ANOVA table shows that the combination of variables significantly predicts the dependent variable. This table clearly stets the predictors and the dependent variables. ANOVA that tests whether the model is significantly better at predicting the outcome than using the mean as a best guess; specifically, the F-ratio represents the ratio of the improvements in the prediction that results from fitting the model, relative to the inaccuracy that still exists in the model. For these data, F is 272.998, which is significant at $\mathrm{P}<0.001$ (because the value in the column labeled sig. is less than 0.001). This result tells us that there is less than a $0.1 \%$ chance that an F-ratio is larger would happen by chance alone. Therefore, we can say that our regression model results in a significantly better prediction of customers' purchase decisions than if we used the 
mean value of customers' purchase decisions.

According to Field (2006), multicollinearity exists when there is a strong correlation between two or more predictors in a regression model. Perfect collinearity exists when at least one predictor is a perfect linear combination of the others. Variance inflation factor (VIF) indicates whether a predictor has a strong linear relationship with the other predictor(s). Tolerance statistics (with tolerance being 1 divided by the VIF), If the largest VIF is greater than 10 then there is cause for concern. If the average is substantially greater than 1 then the regression may be biased. On the other hand, tolerance below 0.1 indicates a serious problem.

Based on this explanation multicollinearity is not the problem of the model. The reason behind this is that all VIF of the model is not above 10. The tolerances of the variables are range between 0.174 and 0.42 . These statistics indicate that multicollinearity is not the problem of the study.

Table 6: Coefficients ${ }^{\mathrm{a}}$

\begin{tabular}{|c|c|c|c|c|c|c|c|}
\hline \multirow[t]{2}{*}{ Model } & \multicolumn{2}{|c|}{$\begin{array}{l}\text { Unstandardized } \\
\text { Coefficients }\end{array}$} & Standardized Coefficients & \multirow[t]{2}{*}{$\mathrm{t}$} & \multirow[t]{2}{*}{ Sig. } & \multicolumn{2}{|c|}{$\begin{array}{l}\text { Collinearity } \\
\text { Statistics }\end{array}$} \\
\hline & $\mathrm{B}$ & Std. Error & Beta & & & Tolerance & VIF \\
\hline (Constant) & .061 & .115 & & .531 & .596 & & \\
\hline Product & .143 & .043 & .143 & 3.341 & .001 & .420 & 2.379 \\
\hline Price & .458 & .061 & .564 & 7.463 & .000 & .136 & 7.371 \\
\hline Promotion & .024 & .075 & .021 & .322 & .748 & .174 & 5.738 \\
\hline Place & .333 & .054 & .284 & 6.201 & .000 & .370 & 2.703 \\
\hline
\end{tabular}

a. Dependent Variable: sales

Table 6 clearly shows that Product, Price, Promotion, and Place have a significant effect on Micro and Small Enterprise Sales turnover.

Therefore, in this study the following multiple regressions were used: Model for the Micro and Small Enterprise marketing mix effect on their sales turnover. The objective of the regression in this study is to find such an equation that could be used to find the impact of predictors on the dependent variable.

The specified regression equation takes the following form:

$\mathrm{Y}=\boldsymbol{\beta 0}+\boldsymbol{\beta 1}(\mathrm{PO})+\beta 2(\mathrm{PI})+\beta 3(\mathrm{PR})+\beta 4(\mathrm{PL})$

Where

Product $=(P O)$, Price $=(P I)$, Promotion $=(P R)$ and Place $(P L)$

So equation comes as

Sales Turnover $=0.061+0.143(P O)+0.458(P I)+0.024(P R)+0.333(P L)$

The significant levels of Product, Price, Promotion, and Place are, .001, .000, .748, and .000 respectively. This test shows that the coefficients of the predictor are statistically significant at less than five percent level of significance.

The $B$ - values tell us about the relationship between sales turnover and each predictor. If the value is positive we can tell that there is a positive relationship between the predictor and the outcome whereas a negative coefficient represents a negative relationship. For these data all four predictors have positive B-value indicates positive relationships.

Each of these beta values have an associated standard error indicated to what extent these values would vary across different samples, and these standard errors are used to determine whether or not the B-value differs significantly from zero.

The B- values and their significance are important statistics to look at. The standardize beta value tells us the number of standard deviations that the outcome was changed as a result of one standard deviation change in the predictor. The standard deviation units and so are directly comparable; therefore, they provide a better insight into the importance of a predictor in the model. The standardize beta value for Price is 0.458 . This indicates that variable has a relatively strong degree of importance for micro and small enterprise sales turnover than the others. The standardized beta value for Product, Promotion, and Place are 0.143, 0.024 and 0.333 respectively. This indicates us these three variables have a comparable degree of importance in the model.

\section{Discussion}

Brassington and Pettitt (2007) indicate that whether a product is a totally innovation, an update of a familiar product or an imitation of a competitor 's product, it needs careful planning and development to ensure that it meets customers 'needs and wants, that it has a significant competitive advantage and that it is accepted within the marketplace. Van Auken, Madrid-Guijarro, Garcia-Perez-de-Lema (2008) believes that innovation facilitates how SMMEs respond to market changes and maintain their competitive advantage. Barrow (2004) state that products and services of a small business enterprise are often faced a quality problem. He continues that consumers often were cheated and defrauded. The result was that small businesses became objects of contempt.

Makgoe (2008: 7) highlights that the location of the small, medium and micro enterprises can have an 
impact on costs. This means that the quality of the local transportation system is vital, as the MSE must be able to deliver the product or services as required by the contract or agreement. The implications of transport costs would, therefore, increase the supplier's final price which makes it extremely difficult for MSEs 'to get business deals or contracts, more especially in rural areas where roads are in a poor condition. However, Kadwa (2004: 40, in Laljit, 2006: 22) indicates that price has become increasingly important as the basis for competition within South African MSEs. This means that businesses use pricing as a strategy for local MSEs. Therefore, this might have a negative impact or take MSEs out of business. Businesses that lack a market orientation are more likely to price their products by simply checking the competition or marking up their costs to achieve the desired profit margin (Best, 2000). There are good odds that these businesses may hurt their customer value, market share and profit margins.

Dawson and Burt (in Findlay and Sparks, 2002: 117) argues that a major influence on the changing structure, performance, and location of retailing is the operational environment in which retail firms must function. This environment encompasses social, economic, technological and political elements that generate a culture to which retailers respond with managerial decisions. However, in the South African context, this changing environment was not investigated to determine whether it has a major influence on the rural SMMEs, particularly in KwaZulu-Natal, which has the second-largest concentration of rural communities in South Africa. Goldberg, Coben, and Fiegenbaum (2003: 168) believe that the reputation of business building is very important. However, they indicate that despite its attractiveness's, few small businesses follow a reputation-building strategy.

Mahadea (2008: 3) indicates that the promotion of MSEs is the focus of considerable policy interest in South Africa and many other countries. However, research conducted by Meyer-Stamer (2003: 9) indicates that South African rural areas seem to be full of problems and bottlenecks where any promotion approach must address several factors at the same time. Clow and Baack (2004: 474) highlight that most small businesses do not have the money to send a marketing message to millions of potential customers. Having developed a product, agreed on its price and selected the most appropriate distribution channel, an organization must promote it to potential buyers (O'Connor and Galvin, 1997: 209). It is usually necessary for the entrepreneur to inform potential consumers about the product's availability or to educate the consumer, using advertising media such as print, radio, or television (Hisrich and Peters, 1998: 275). The entrepreneur should carefully evaluate each alternative medium, considering not just costs but the effectiveness of the medium in meeting the market objectives.

The study on MSEs has revealed that there has been a phenomenal growth in the number of MSEs and the size of employment generated by the sector in the last few years. Moreover, the growing tendency to be selfemployed by many young university graduates instead of waiting for employment from the public or private sector has been encouraging (Ethiopian Economic Association (EEA), 2015).

Although improvements have been registered during the last few years, the performances of MSE have fallen short of expectations due to various challenges. These include problems related to finance, access to market and low competitiveness, business information, working premises, poor acquisition of technical skills and managerial expertise, appropriate technology, and access to quality infrastructure (Ethiopian Economic Association (EEA), 2015).

Marketing concept of building an organization around the profitable satisfaction of customer needs have helped firms to achieve success in high-growth, moderately competitive markets. However, to be successful in markets in which economic growth has leveled and in which there exist many competitors who follow the marketing concept, a well-developed marketing strategy that considers a portfolio of products, takes into account the anticipated moves of competitors in the market and develops effective responses to changing market environments is required (Rijgut, 2012).

The study intended to reach respondents have worked in the MSEs for a duration that was sufficient for them to understand the marketing strategies which was being used. The majority of the respondents were aged between thirty-one to forty years with varying work durations with a majority having worked for less than ten years; this matches the duration in which the majority of the MSEs have been in existence. The respondents reached were therefore conversant with the marketing strategies employed in the MSE (Rijgut, 2012).

\section{Conclusion}

Micro and small enterprise product and their sales turnover have a positive and strong relationship and this relationship also benefits MSEs for future success. While MSEs focus on products, they have to give attention to product quality and consistency. The main reason is that local customers have low priority for MSE's product than an imported one. The issue of product quality consistency and branding is very essential for MSE sales turnover. Product quality enhancement is difficult to achieve alone by MSEs so, they should have to create a partnership with technical and vocational schools and they have to focus on maximization of the productivity and brand building. 
Pricing issues of MSE is one variable that significantly affects their sales turnover. Of course, MSE run their business with limited financial resources, so, they may want to increase the price of their product to increase their running capital. Due to customers' expectation about the price of MSE product, they should be wise and sale products at the fair or low-profit margin and increases sales to increase their productivity instead of selling a few goods at a high-profit margin. Another important point MSE should consider while doing their business, their pricing should not be constant for a long period of time, and they have to revise it periodically.

The finding of this study indicates that promotion is insignificant for MSE sales turnover. This does not mean that MSEs should not engage in any promotional activities. However, MSE prefers a different promotional method that the traditional promotional-mix. Customers may prefer to buy products from MSE based on the information they get from their family, friends or due to familiarity with the business. So, using formal methods of promotion have an insignificant effect on the sales turnover of MSE.

One of the marketing-mix which has an effect on MSE sales turnover is place or distribution. The product most of the time produced by MSE in Ethiopia particularly in Dire Dawa are consumables goods. The sales proximity for the customers has a huge effect on sales turnover enhancement. The distribution of MSE does not mean that they should have to follow the long chain to sell their products. Opening their production site close to consumers and opening different branches' is the expected strategy expected from MSE regarding Place decision.

MSE has some marketing related opportunities in Dire Dawa City Administration. The City administration works on creating conducive marketing environment for MSE by arranging different programs. MSE is got a chance to participate in difference governmental projects exclusively. Of course, the city administration did not sufficiently support for MSE regarding creating conducive marketing environment. But, they have begun some activities to support MSE marketing efforts.

Even if MSE in Dire Dawa has opportunities regarding marketing and another aspect, they have their own challenges. One of the major challenges of MSE in Dire Dawa is market-related. They do not have sufficient salesroom, their production site far from customer's residence, low cooperating between a different government office and insufficient knowledge of marketing and business. Even owners of MSE do not believe the value of MSE and they participate as a secondary business.

\section{Recommendation}

MSE owners in Dire Dawa should be careful with their product quality, consistency and branding issues in order to enhance their sales turnover. The product should be considering the local customers' need and they should work with their customers to fulfill their needs. MSE should not produce products because they can produce; they have started from what really the customers need.

MSE should be careful of the price of their products, because customer perception towards MSE and the customers' level of income affect their decision. The owner of MSE gives priority to sales more at fewer profit margins than sales few at a higher profit margin.

Promotions of MSE have an insignificant effect on their sales turnover. So, they have to focus on other kinds of communication rather than traditional promotion mix. They give attention to personal communication like word of mouth or direct marketing.

The place or distribution of MSE is very essential for them and require their full attention. So, MSE should work together to get a place in the appropriate place in the city to sell their products. Otherwise actively attend any bazar in the city to sell their products.

Even if the marketing opportunity in the Dire Dawa City Administration is not sufficient, utilization of these opportunities has its own problems. All MSE should be aware that they are efficiently utilizing the available opportunities or not in the city.

The final recommendation for MSE in Dire Dawa is handling marketing challenges in Dire Dawa. The marketing challenges of MSE in Dire Dawa emanated from the owner of MSE, from different government officials and from society. So, MSE owners start dealing with the challenge which emanates from them. In addition to this, they should have worked hard to show their capacity, willingness to get support from the government. They should not give up easily by a few challenges. Regarding the challenge emanated from society very difficult to change. So, it is better to follow it.

\section{Suggestion for Future Studies}

With the nature of this study is exploratory and quantitative with some qualitative, the researcher has provided an ideal base of knowledge to support many studies in the future. The results have uncovered are broad, meaning that many topic areas are covered, but there is still much room for expansion of knowledge and theory. In addition, the suggested methodology in this study takes survey methods and interview for urban food securing and job creation agency in Dire Dawa.

This research conducted on marketing challenges of MSE and its effect on their sales turnover by identifying marketing mix variables such as product, price, promotion and place and the challenge and 
opportunity MSE faced in Dire Dawa.

Future studies could look into which of the Marketing mix variable have the most influence on sale turnover of MSE. This study only focused on the marketing the challenge, but other challenges like business ethics, government support infrastructure can be seen as variables for future research.

In addition, future studies could look more closely into the relationship between MSE's personal commitment to handling marketing or other challenges and the potential growth possibility of MSE in Dire Dawa.

\section{Reference}

Abdulmelike, A., Bese, S., Sime, G., Ejigu, F., and Mama, M. (2018). Challenges and Opportunities of MSEs in Ethiopia: A Review Paper. Journal of Economics and Sustainable Development, Vol.9, No.19, pp 68-74.

Abera, Y. (2016). Market Challenges and Opportunities of Micro and Small Scale Enterprises in Dire Dawa, Ethiopia, Natrual resource, agricultural development and food security- international research network, volume 16 , issue $01,1-32$.

Abera, Y. (2016). Market Challenges and Opportunities of Micro and Small Scale Enterprises in Dire Dawa, Ethiopia. Natural Resource, Agricultural Development, and Food security International Research work, $16(1), 1-32$.

Accountingtools.com (February 8, 2018). Sales Turnover. Retrieved in September 30, 2019 from https://www.accountingtools.com/articles/what-is-sales-turnover.html

Ardjouman, D. and Asma, B. (2015). Marketing Management Strategies Affecting Performance of Small and Medium Enterprises (SMEs) in Cote d'Ivoire. International Journal of Business and Social Science Vol. 6, No. 4; pp141-150

Aruna,. N. (2015). Problems Faced By Micro, Small and Medium Enterprises - A Special Reference to Small Entrepreneurs in Visakhapatnam, IOSR Journal of Business and Management (IOSR-JBM) e-ISSN: 2278487X, p-ISSN: 2319-7668. Volume 17, Issue 4.Ver. V (Apr. 2015), PP 43-49.

Ashwini, C. (2012). Marketing Potentials of Small and Medium Enterprises In Fiji. (Thesis) Master of Commerce, The University of the South Pacific,

Ayuba, E. \& Gakure, R. (2014). Effects of Marketing Strategies, 4Ps of Marketing Elements and Firm Resources on the Performance of Small and Medium Enterprises in Nigeria. International Journal of Advanced Research in Statistics, Management and Finance Vol. 2 No. 1, pp102-117.

Beck, T. and Levine, R. 2003. Small and medium enterprises, growth and poverty: cross country evidence. New York: World Bank.

Belay, G. 2000. Evaluation of the performance of the private sector economy in Ethiopia (1991- 1999). Addis Ababa: Ethiopian Ministry of Trade and Industry.

Cambridge dictionary, https://dictionary.cambridge.org/dictionary/english/sales-turnover retrieved September 30,2019

Cant, M. C. \& Wiid, J. A. (2013). Establishing The Challenges Affecting South African, SMEs, International Business \& Economics Research Journal - June 2013 Volume 12, Number 6, pp 707-716.

Central Statistical Authority (CSA). 2003. Urban informal sector sample survey. Addis Ababa: Central Statistical Authority of Ethiopia.

Chaudhary, G. (2014). A Study on Marketing Aspect of Medium and Small Enterprises. International Journal of Emerging Research in Management \&Technology. Volume-3, Issue-10. Pp 40-48.

Debitoor.com (2019). Sales turnover - What is sales turnover? Retrieved from https://debitoor.com/dictionary/sales-turnover. Sep 24, 2019

Ethiopian Economic Association (EEA). (2015). Small and Micro Enterprises (SMEs) Development in Ethiopia: Policies, Performances, Constraints and Prospects. Issue No. 5, February 2015. www.eeaecon.org.

Ezekiel, T., Juliet, A., \& Patricia, A. (2015) Marketing Problems and the Performance of Selected Small and Medium Enterprises (SMEs) in Southern Senatorial District of Cross River State, Nigeria. American International Journal of Contemporary Research Vol. 5, No. 5; p 70-76.

Gebeyehu, W. and Assefa, D. 2004. Role of micro and small enterprises in the economic development of Ethiopia. Addis Ababa: Federal Micro and Small Enterprises Agency.

Gebrehiowot, A. and Wolday, A. 2004. Policy impact on regulatory challenges of the micro and small enterprises in Ethiopia. Proceedings of the 2nd International Conference on the Ethiopian Economy. Addis Ababa: Ethiopian Economic Association.

Ghafoor, A. and Hashmi, S. (2014). Marketing Practices Of Small \& Medium Size Enterprises: A Case Study Of SME'S In Multan District. European Journal of Business and Innovation Research, Vol.2, No.6, pp.9-20.

Kebede, M.S., (2015), Challenges and Prospects of Small Enterprises in Ethiopia: A Study of Entrepreneurs in Tigray Region, (PhD dissertation), University of South Africa, October 2015

Ken, K. 2003. Maximising the benefits of globalisation for Africa. Proceedings of International Conference on 
Trade and Investment. Dakar, 23-26 April.

Kotler, P. and Armstrong, G. (2010). Principles of Marketing, $13^{\text {th }}$ Edition, published by Pearson Education, Inc., Upper Saddle River, New Jersey, 07458.

Mechalu, A. (2017). Marketing Challenges of Micro and Small Enterprises (MSEs) in Bishoftu Town. Masters of Art Degree in Marketing Management, Addis Ababa University, Addis Ababa, Ethiopia.

Ministry of Urban Development \& Construction (MoUDC), (2013). Survey on Micro and Small Enterprises (MSEs) in Selected Major Cities of Ethiopia. Addis Ababa.

Mpele, L. (2010). The Use of Marketing Strategies by Small, Medium and Micro Enterprises in Rural KwaZuluNatal. Doctor Degree of Technology: Marketing in the Faculty of Management Sciences at the Durban University of Technology. Durban University of technology, South Africa.

Mutoko, W. (2014). Challenges of Access to Markets And Opportunities For Small, Medium And Micro Enterprises (SMMES) In Botswana. European Scientific Journal August 2014 /SPECIAL/ edition. Pp28-38

Negash, Z and Kena, T. 2003. State, growth and dynamism of micro and small enterprises in Mekele. Mekele University of Ethiopia: Microfinance Program and Economic Development.

OECD,(2005). Encouraging linkages between small and medium-sized companies and multinational enterprises. An overview of good policy practice.

Olayemi, S. and Wahid, K. (2014). Marketing Challenges and Opportunities Confronting Small Scale Businesses in Nigeria - A Lesson for Young Entrepreneur. Journal of Poverty, Investment and Development, Vol.5. pp118-125

Paul I. and Rahel, W. 2010. Growth determinants of women-operated micro and small enterprises in Tigray region. Journal of Sustainable Development in Africa, 25(6).

Perreault, W., Cannon, J. and McCarthy, J. (2012). Essentials of Marketing: A Marketing Strategy Planning Approach. $13^{\text {th }}$ edition, Published by McGraw-Hill/Irwin, a business unit of The McGraw-Hill Companies, Inc., 1221 Avenue of the Americas, New York, NY, 10020.

Pride, W. and Ferrell, O. (2015). Foundations of Marketing, $6^{\text {th }}$ Edition. Published by Cengage Learning, 200 First Stamford Place, 4th Floor, Stamford, CT 06902, USA.

Rijgut, M. (2012). Marketing Strategies Adopted By Small And Medium Enterprises In Nairobi Central Business District. Degree of Master of Business Administration (MBA), School of Business, University of Nairobi.

Siddiqui, M.A. (2015). Problems and Challenges of MSMEs in Telangana, international journal of business quantitative economic and applied management Research, Volume 1, Issue 11, pp: 54-66

Solymossy, E. and Penna, A.A. 2000. Sustainable growth for the small business: a theory of organizational transition. Illinois: Western Illinois University.

Srinivasan, Prof. Resham Bajaj \& Dr. Sandeep Bhanot (2016), Impact of Social Media Marketing Strategies used by Micro Small and Medium Enterprises (MSMEs) on Customer acquisition and retention, IOSR Journal of Business and Management (IOSR- JBM). Volume 18, Issue 1 .Ver. III (Jan. 2016), PP 91-101. 